\title{
Effects of $\mathrm{I}_{2}$ on $\mathrm{Cu}_{2-x} S$ nanoparticles: Enabling cation exchange but complicating plasmonics
}

Han K.D. Le, ${ }^{\ddagger}$ Huiyan Xiong, Bonnie A. Page, Luis F. Garcia-Herrera, Haley P. McAllister, Boxi Cameron Li, $†$ Haiying Wang, ${ }^{\S}$ and Katherine E. Plass*

EXPERIMENTAL METHODS

SI-2

ADDITIONAL DATA

Figure S1. Additional and enlarged UV/visible/NIR spectra of $\mathrm{I}_{2}$-exposed roxbyite nanoplatelets

SI-5

Figure S2. PXRD of roxbyite nanoplatelets before and after $\mathrm{I}_{2}$ exposure without ethanol washing.

SI-6

Figure S3. EDS data before and after washing with methanol or ethanol.

SI-6

Figure S4. ICP data showing the change in the $\mathrm{Cu} / \mathrm{S}$ mole ratio with increasing $\mathrm{I}_{2}$ exposure.

Figure S5. Expanded PXRD of nanorods exposed to different amounts of $\mathrm{I}_{2}$.

SI-7

Figure S6. HR-TEM of roxbyite nanorods before and after $I_{2}$ exposure.

SI-7

Figure S7. HAADF image and $\mathrm{Cu}, \mathrm{S}$, and $\mathrm{Cd}$ maps for nanorods.

SI-8

Figure S8. TEM of roxbyite nanoplatelets before and after $\mathrm{I}_{2}$-exposure and/or cation exchange.

Figure S9. ICP data for platelets before and after $\mathrm{Zn}^{2+}$ exchange.

SI-9

Figure S10. PXRD of roxbyite nanoplatelets after 24 hours of room temperature exchange with $\mathrm{Cd}^{2+}$. 


\section{EXPERIMENTAL SECTION}

\section{Chemicals}

The reagents used for the synthesis of roxbyite nanoparticles include copper nitrate dihydrate $\left(\mathrm{Cu}\left(\mathrm{NO}_{3}\right)_{2} \cdot 3 \mathrm{H}_{2} \mathrm{O}, 99.95 \%\right)$, copper acetylacetonate $\left(\mathrm{Cu}(\mathrm{acac})_{2}, 99.9 \%\right)$, sulfur powder (99.98\%), trioctylphosphine oxide ( $\left.\geq 90 \%\right)$, oleylamine (technical grade, $\left.70 \%\right)$, 1-octadecene (technical grade, 90\%), tert-dodecyl mercaptan (mixture of isomers, 98.5\%), and 1-dodecanethiol ( $\geq 98 \%$ ). Additional reagents used for the cation exchange include cadmium(II) acetate dihydrate $\left(\mathrm{Cd}(\mathrm{OAc})_{2} \cdot 2 \mathrm{H}_{2} \mathrm{O}, 99.999 \%\right.$ trace metal basis), zinc chloride $\left(\mathrm{ZnCl}_{2}, 98 \%\right.$, Sigma-Aldrich, stored in dry box), dibenzyl ether (99\%), trioctylphosphine $(\geq 85 \%)$. Additional reagents used for $\mathrm{I}_{2}$ treatment include elemental iodine $\geq 99.8 \%$ ) anhydrous tetrahydrofuran (THF, DriSolv) or anhydrous methanol (99.8\%). All solvents used for precipitation and washing of nanoparticles, including isopropyl alcohol (IPA), toluene, hexane, and acetone, were of analytical grade. Unless specified, all reagents were purchased from Sigma-Aldrich and used as received.

\section{Synthesis of roxbyite nanorods}

$\mathrm{Cu}_{1.8} \mathrm{~S}$ nanorods were synthesized using a modified published procedure. ${ }^{1,2}$ The synthesis was performed under the Schlenk line. $\mathrm{Cu}\left(\mathrm{NO}_{3}\right)_{2} \cdot 3 \mathrm{H}_{2} \mathrm{O}(281 \mathrm{mg})$, trioctylphosphine oxide $(2.9 \mathrm{~g})$, and octadecene $(15 \mathrm{~mL})$ were combined in a $50 \mathrm{~mL}$ 3-neck flask, and placed under vacuum. A type-K penetration thermocouple probe and an expanded-range thermometer were used to monitor the temperature. This mixture was degassed at $80^{\circ} \mathrm{C}$ for 30 minutes, resulting in a blue solution. It is critical that the degassing temperature does not exceed $83{ }^{\circ} \mathrm{C}$. In the meantime, a mixture of $15 \mathrm{~mL}$ tert-dodecyl mercaptan and $1.5 \mathrm{~mL}$ 1-dodecanethiol was prepared and degassed until the hot injection period. After the degassing period, the flask containing the copper precursor was cycled with Ar and vacuum three times, with each cycle lasting 5 minutes. The flask was then placed under a blanket of Ar, and the reaction temperature was increased to $180^{\circ} \mathrm{C}$ within $5-10$ minutes by placing the flask in a pre-heated heating mantle at $240^{\circ} \mathrm{C}$. As the temperature was increasing, $7.5 \mathrm{~mL}$ of a 10:1 mixture of tert-dodecyl mercaptan: 1 dodecanethiol was rapidly injected at $135^{\circ} \mathrm{C}$, resulting in a green/yellow-colored solution. When the temperature reached $180{ }^{\circ} \mathrm{C}$, the solution will become dark but not turbid, indicating the formation of $\mathrm{Cu}_{2-\mathrm{x}} \mathrm{S} \mathrm{NPs}$. When the solution becomes turbid, which is when the temperature has fallen in $180^{\circ} \mathrm{C}-185^{\circ} \mathrm{C}$ for 5 minutes, the flask was then held at this temperature range for 15 minutes to allow for the one-dimensional growth of the $\mathrm{Cu}_{1.8} \mathrm{~S}$ NPs. It is important to overshoot the temperature rather than undershoot it, since no rod growth would occur under $180^{\circ} \mathrm{C}$. After the growth time, the flask was cooled rapidly by removing the heating mantle and placing the flask into a room temperature water bath. When the temperature is at $\sim 40^{\circ} \mathrm{C}, 2 \mathrm{~mL}$ of toluene was injected into the reaction mixture. The resulting product was precipitated with $20 \mathrm{~mL}$ of IPA, followed by centrifugation for 10 minutes at $6000 \mathrm{rpm}$ and resuspension in hexane. The particles were then washed three more times with IPA and hexane, with 3 drops of oleylamine added between the first wash and the second wash. The final brown product was resuspended in $4 \mathrm{~mL}$ of hexanes for characterization and use in further reactions. Synthesis of roxbyite nanoparticles has been carried out regularly in our lab over the past year. Variations in aspect ratio are common, though the nanorod shape is always present. For this reason, $\mathrm{I}_{2}$-treated samples were always compared to controls from the same synthetic batch. Variation in phase was observed on 1 or 2 occasions, where monoclinic chalcocite was obtained rather than roxbyite.

\section{Synthesis of roxbyite nanoplatelets}

$\mathrm{Cu}_{1.8} \mathrm{~S}$ nanoplatelets were synthesized using a modified published procedure. ${ }^{3}$ Copper acetylacetonate ( $515 \mathrm{mg}$, $\left.1.97 \mathrm{mmol}\right)$, sulfur powder $(35 \mathrm{mg}, 1.09 \mathrm{mmol})$, and oleylamine $(20 \mathrm{~mL})$ were combined in a $100 \mathrm{~mL}$ 2-neck round bottom flask. After degassing the mixture for about twenty minutes at room temperature, it was degassed for an isochronal amount of time at $110^{\circ} \mathrm{C}$. The mixture was then heated under argon flow for one hour at $200^{\circ} \mathrm{C}$ before cooling to room temperature. Hexanes and ethanol were used to clean the mixture before being centrifuged for ten minutes at 6,000 RPM for a total of three times. This process yielded a brown-colored solution. Once the synthesis and the washing were complete, particles were suspended in hexane and transferred to a purged septum vial. Synthesis of roxbyite nanoplatelets has been carried out regularly in our laboratory over the past few years with reproducible size, phase, and morphology.

\section{Oxidation of roxbyite particles with $\mathrm{I}_{2}$}

A $0.02 \mathrm{M} \mathrm{I}_{2}$ solution in THF was prepared in a $20-\mathrm{mL}$, septum-capped vial covered with tin foil and electrical tape ( $\mathrm{I}_{2}$ in solution is lightsensitive), and the solution was stirred for 15 minutes at room temperature. In the meantime, a specified amount of $\mathrm{Cu}_{1.8} \mathrm{~S}$ nanoparticle suspension in hexane (10-40 mg of particles) was dried under Ar in septum-capped vial and THF was added to make a $5 \mathrm{mg} / \mathrm{mL}$ suspension. The $\mathrm{Cu}_{1.8} \mathrm{~S}$ nanoparticle/THF suspension was sonicated for 5 minutes, and the vial was then covered with tin foil and electrical tape. The $\mathrm{I}_{2}$ solution was injected into the vial containing $\mathrm{Cu}_{1.8} \mathrm{~S}$ nanoparticles. Unless otherwise specified, $10.0 \mu \mathrm{L} \mathrm{I} \mathrm{I}_{2}$ solution/mg seed particles $\left(0.2 \mu \mathrm{mol} \mathrm{I}_{2} / \mathrm{mg}\right.$ particles) was used, though experiments varied from 3.0-20.0 $\mu \mathrm{L} \mathrm{I}_{2}$ solution $/ \mathrm{mg}$ seed particles. The $\mathrm{I}_{2}$-treated particles were then sonicated for 5 minutes and stirred for 15 minutes. The oxidation of roxbyite particles with $\mathrm{I}_{2}$, followed by the optimized washing procedure, has been carried out in our laboratory at least 10 times. The finding that the post-washing, $\mathrm{I}_{2}$-treated particles showed a red-shifted plasmon band and band gap compared to the control was reproduced at least three times. The in-situ $\mathrm{I}_{2}$-treatment, showing the initial enhancement of the plasmon band followed by a gradual relaxation was repeated at least three times.

Iodine washing optimization For the washing step, the resulting treated particles were precipitated with $20 \mathrm{~mL}$ of IPA, followed by centrifugation for 10 minutes at $6000 \mathrm{rpm}$ and resuspension in hexane. The particles were then washed with $20 \mathrm{~mL}$ IPA and centrifuged for $10 \mathrm{minutes}$ at $6000 \mathrm{rpm}$. The supernatant was then discarded, and the centrifuged product was resuspended in hexane. The particles were again washed with $15 \mathrm{~mL}$ of EtOH. Upon addition of EtOH the particles seemed to aggregate significantly and fell down to the bottom of the centrifuge tube. The supernatant after this washing step looked pinkish/purple. Oleylamine ( 3 drops) was added to prevent particle aggregation. The product were again washed twice with $15 \mathrm{~mL}$ of IPA and the final product was resuspended in hexanes for characterization and use in further reactions. 
Effect on colloidal stability The iodine treatment altered the colloidal stability. As-synthesized particle suspensions in hexane with a few drops of oleylamine ligand remained stable for 10-14 days. The iodine-treated particles, however, have reduced stability. They precipitate from solution after several days, despite the addition of stabilizing ligands. The behavior is attributable to the extensive washing process, which might be exacerbated by the displacement of ligands by iodine. Surface passivation by $\mathrm{I}_{2}$ been observed in $\mathrm{PbS}$ particles ${ }^{4,5}$ and $\mathrm{I}_{2}$ has been reported to accelerate ligand exchange in $\mathrm{CuInS}_{2}$ nanoparticles. ${ }^{6} \mathrm{XPS}$, however, shows little surface iodine $(0.1 \mathrm{~mol} \%)$ indicating that little $\mathrm{I}_{2}$ or I- remains on the surface. This is not expected to influence the cation exchange behavior. Particles are sonicated with trioctylphosphine for 45 min before cation exchange. Post-cation exchange, the colloidal stability is similar to the control particles with particle suspensions remaining stable without additional ligand addition for 10-14 days.

\section{$\mathrm{Cd}^{2+}$ cation exchange}

Cation exchange reactions with $\mathrm{Cd}^{2+}$ were performed using slight modifications to a published procedure. ${ }^{2} \mathrm{In}$ a 50 -mL 3 -neck flask $\mathrm{Cd}(\mathrm{OAc})_{2} \cdot{ }_{2} \mathrm{H}_{2} \mathrm{O}(245 \mathrm{mg})$, oleylamine $(8 \mathrm{~mL})$, octadecene $(2 \mathrm{~mL})$, and benzyl ether $(15 \mathrm{~mL})$ were combined, degassed at $100{ }^{\circ} \mathrm{C}$ for 60 minutes, and then cooled to $50{ }^{\circ} \mathrm{C}$. During this time, the desired amount of $\mathrm{Cu}_{1.8} \mathrm{~S}$ nanoparticles ( $15 \mathrm{mg}$ to $40 \mathrm{mg}$ ) were transferred in a green vial, dried under $\mathrm{Ar}$ and resuspended in trioctylphosphine ( $3 \mathrm{~mL}$ for $15 \mathrm{mg}$ nanoparticles to $6.5 \mathrm{~mL}$ for $40 \mathrm{mg}$ nanoparticles). It is important to note that a strictly air-free environment needs to be maintained throughout the course of the reaction because $\mathrm{Cu}_{1.8} \mathrm{~S}$ nanoparticles are easily etched in the presence of trioctylphosphine and oxygen. Hence, vials and flasks containing nanoparticle and trioctylphosphine were purged with Ar immediately before and after all of the injection steps for 3 minutes. After trioctylphosphine injection, the vial was thoroughly parafilmed and sonicated for 45 minutes. The nanoparticle/ trioctylphosphine suspension was then rapidly injected into the reaction flask at $50{ }^{\circ} \mathrm{C}$ and allowed to exchange for a specified amount of time (30 minutes to 2.5 hours). The reaction mixture was then quenched with injection of $2 \mathrm{~mL}$ ice-cold acetone into the flask, and quickly transferred into centrifuge tubes. The centrifuge tubes were placed into an ice bath to ensure reaction completion. The resulting product was precipitated with $20 \mathrm{~mL}$ of IPA, followed by centrifugation for 10 minutes at $6000 \mathrm{rpm}$ and resuspension in hexane. The particles were then washed two more times with IPA and hexane, and the final product was resuspended in $4 \mathrm{~mL}$ of hexanes for characterization and use in further reactions. The general finding that $\mathrm{I}_{2}$ - exposure enhanced $\mathrm{Cd}^{2+}$ exchange was confirmed in the roxbyite nanorod and nanoparticle systems at least 8 times in the past several months. The finding that the zinc blende phase of CdS was obtained with sufficient $\mathrm{I}_{2}$-treatment was observed at least twice. It was observed once upon treating nanorods with $0.3 \mu \mathrm{mol} \mathrm{I}_{2} / \mathrm{mg}$ particles followed by 30 min cation exchange at $50^{\circ} \mathrm{C}$, but not for lower amounts of $\mathrm{I}_{2}$-treatment of particles from the same batch tested at the same time. It was further confirmed by $\mathrm{I}_{2}$-treatment of roxbyite nanoplatelets that were cation-exchanged at room temperature overnight.

\section{$\mathrm{Zn}^{2+}$ cation exchange}

Cation exchange reactions with $\mathrm{Zn}^{2+}$ were performed using slight modifications to a published procedure. ${ }^{2} \mathrm{Zinc}$ chloride (350 mg, 1.83 $\mathrm{mmol})$, oleylamine $(8 \mathrm{~mL})$, octadecene $(2 \mathrm{~mL})$, and dibenzyl ether $(15 \mathrm{~mL})$ were combined in a $50 \mathrm{~mL}$ 3-neck round bottom flask. The mixture was first degassed for thirty minutes at $110^{\circ} \mathrm{C}$ under vacuum, then ramped up to $180^{\circ} \mathrm{C}$ for thirty more minutes under argon flow to synthesize the complex. The mixture was degassed once again for sixty minutes under argon flow at $130^{\circ} \mathrm{C}$. During this step, vacuum was pulled briefly in order to pull off unwanted vapor; this lasted for about five to ten minutes or until bubbling has ceased. The mixture is then allowed to cool to $50{ }^{\circ} \mathrm{C}$, the temperature at which cation exchange will later occur.

Roxbyite seeds suspended in trioctylphosphine $(3 \mathrm{~mL})$ were injected via syringe into a $50 \mathrm{~mL}$ 3-neck round bottom flask containing zinc complex at $50^{\circ} \mathrm{C}$. The particles were allowed to undergo exchange for ten to fifteen minutes under argon flow. Once the appropriate amount of time had passed, $5 \mathrm{~mL}$ of cold acetone were injected into the flask. The flask was then lowered into an ice bath and left alone until the flask contents had reached $20^{\circ} \mathrm{C}$. The exchange products were combined with isopropanol and centrifuged for five minutes at 6,000 RPM. More isopropanol as well as hexanes were used to wash the particles a second time. The final compound was stored in a purged septum vial. The finding that $\mathrm{I}_{2}$-exposure enhanced $\mathrm{Zn}^{2+}$ cation exchange in roxbyite nanoplatelets was confirmed by comparing an $\mathrm{I}_{2}$-treated samples $(0.2 \mu$ mol $\mathrm{I}_{2} / \mathrm{mg}$ particles) to an untreated control at least four times.

\section{Characterization}

UV-visible-NIR Absorption Spectroscopy. In each NIR cuvette, $200 \mu \mathrm{L}$ of a $5 \mathrm{mg} / \mathrm{mL}$ particle-THF solution was added to $3 \mathrm{~mL}$ of THF. UV-vis-NIR spectra were obtained using a Perkin-Elmer Lambda 950 spectrometer with an integrating sphere with InGaS and PMT detectors. The range was typically set from 200 to $1500 \mathrm{~nm}$, with a data interval of $2 \mathrm{~nm}$.

Powder X-Ray Diffraction (PXRD). After nanoparticles were cleaned and resuspended in hexane, they were cast onto glass slides and allowed to dry, then covered with Parafilm to avoid exposure to solid nanoparticles. The PXRD data were collected using a PANalytical X'Pert Pro X-ray diffractometer. The samples were scanned with 10 repetitions at a current of $40 \mathrm{~mA}$ and voltage of $45 \mathrm{kV}$. Using the PANalytical HighScore Plus software, the ten scans were summed and compared peaks with patterns from the ICDD database to determine the structure of the nanoparticles.

Transmission Electron Microscopy (TEM). Samples were prepared by placing a drop of nanoparticles suspended in hexane or toluene on a Ni-supported ultra-thin carbon-coated TEM grid (Electron Microscopy Sciences). TEM images of the particles and their average sizes were obtained under $25 \mathrm{kV}$ with the Delong America LVEM25 Low-Voltage TEM and the Zyla 5.5 Scientific CMOS camera with appropriate alignments and enhancements. TEM images were analyzed using ImageJ software.

Scanning electron microscopy/Energy-dispersive X-ray spectroscopy (SEM/EDS). Nanoparticles suspended in hexane were allowed to dry and then uniformly immobilized on a small piece of conductive carbon tape. SEM and EDS of the sample were then carried out at $20 \mathrm{kV}$ with the Evex Mini-SEM. 
HAADF STEM/EDS mapping. Samples were prepared by placing a drop of nanoparticles suspended in hexane or toluene on a Ni-supported ultra-thin carbon-coated TEM grid (Electron Microscopy Sciences). The microscope employed was an FEI Talos F200X with a SuperX EDS at $200 \mathrm{kV}$ in the Materials Characterization Laboratory at the Pennsylvania State University.

Inductively coupled plasma-Atomic emission spectroscopy (ICP-AES). Samples were microwave digested in concentrated nitric acid (5 mL, SCP Science, Plasma Pure) using a CEM MARS microwave digester and EPA 3051_16 method. Samples were then diluted to give a matrix of $5 \%$ nitric acid in water (Milli-Q purified, $18 \Omega \bullet \mathrm{cm}$ ). Calibration standards with the same matrix were obtained by dilution of $100 \mathrm{ppm}$ Inorganic Venture standards to give standards with concentrations between $1.00 \times 10^{-2}$ and $5.00 \mathrm{ppm} . \mathrm{Cu}(324.754 \mathrm{and} 327.396 \mathrm{~nm}$ lines), Cd (214.438, 226.502, and 228.802 nm lines), $\mathrm{Zn}(202.613,206.200$, and $213.856 \mathrm{~nm}$ lines) and S (182.034, 180.731, and 166.68 nm lines) were measured. The average and standard deviation of all wavelengths was obtained for each element. Measurements were made using an Ametek SpectroBlue instrument. 

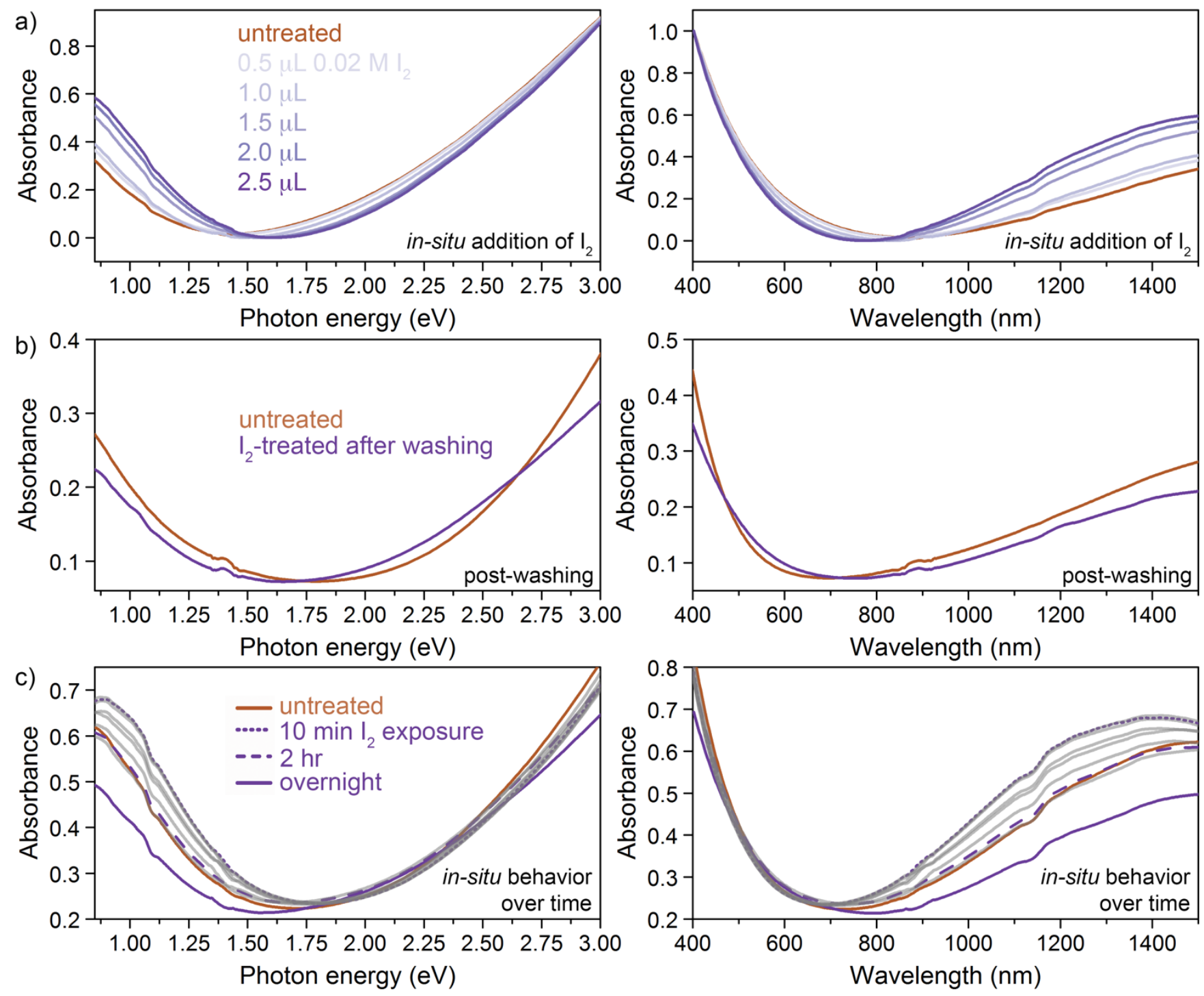

Figure S1. UV/visible/NIR absorption spectra of roxbyite nanoplatlets treated with $0.02 \mathrm{M} \mathrm{I}_{2}$ in THF. a) In-situ addition of increasing amounts of $\mathrm{I}_{2}$ shows how the plasmon band at $\sim 0.8 \mathrm{eV}$ shifts and grows at the same time the band gap onset shifts from $1.3 \mathrm{eV}$ to $1.7 \mathrm{eV}$. Analogous behavior was observed by Jain et al..$^{7}$ and Hartstein et al.. ${ }^{8}$ b) Spectra of roxbyite nanoplatelets before and after $\mathrm{I}_{2}$-exposure, precipitation, and cleaning $(1 \mathrm{mg} / \mathrm{mL}$ in THF). Unlike in the in-situ situation, $\mathrm{I}_{2}$ oxidation results in a decrease in the height of the plasmon band and a red-shift in both the band gap onset and plasmon band. c) Spectra of roxbyite nanoplatlets over time after injection of $\mathrm{I}_{2}$. The plasmon band increases in intensity and blue-shifts for the first 10 min after injection, returning to pre-exposure behavior after 2 hours and resembling the post-washing spectrum in b after overnight exposure. 


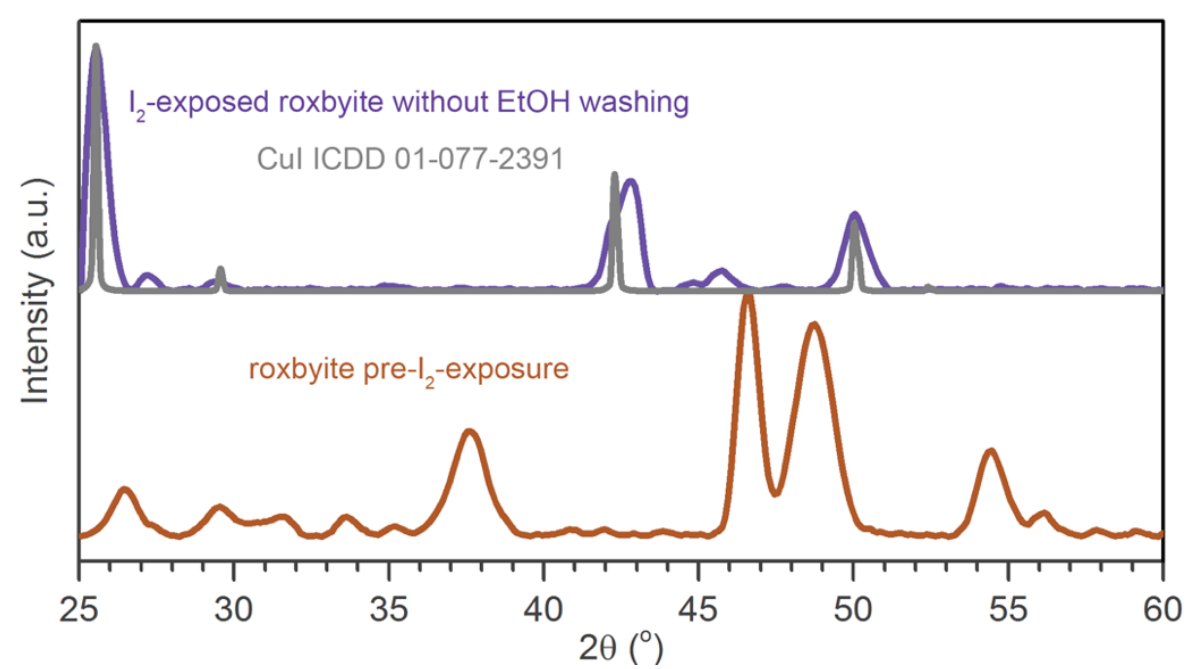

Figure S2. PXRD of roxbyite nanoplatelets before and after $\mathrm{I}_{2}$ exposure without ethanol washing, revealing the presence of CuI in the unwashed samples.

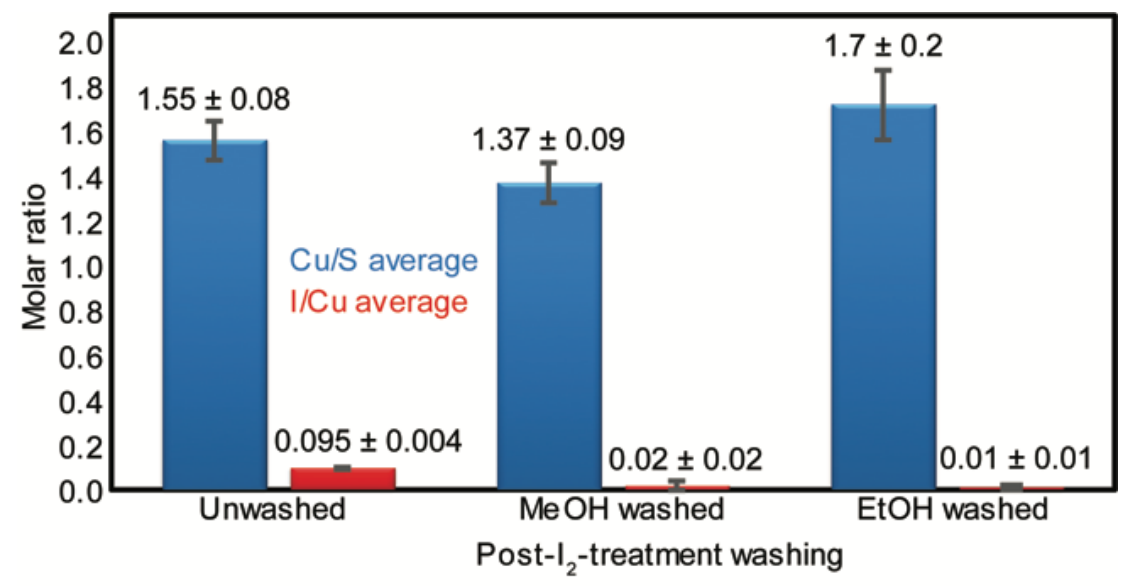

Figure S3. EDS data showing that washing with methanol or ethanol post- $\mathrm{I}_{2}$-treatment is necessary to remove iodine. Ethanol was chosen due to the smaller effect on the $\mathrm{CuS}$ ratio compared to the pre-I $\mathrm{I}_{2}$-treatment value of $1.6 \pm 0.1$.

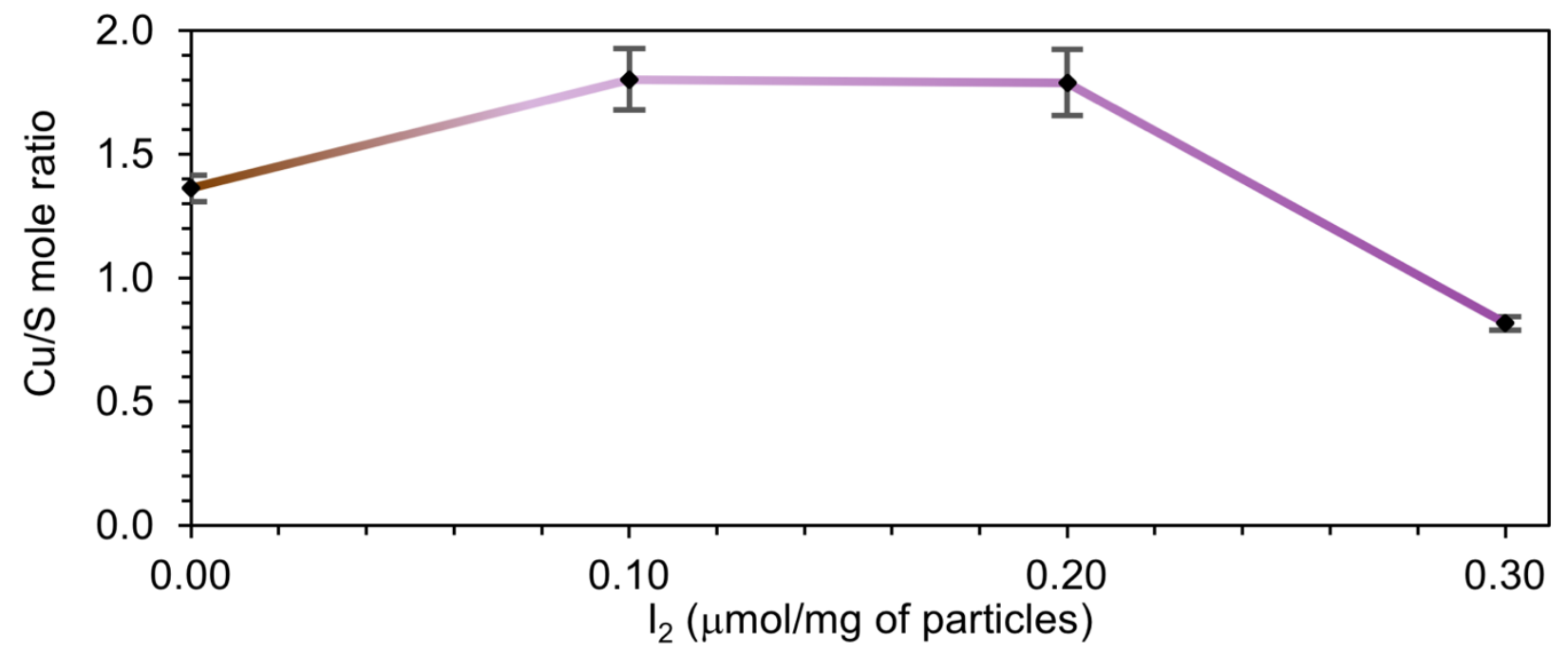

Figure S4. ICP data showing the change in the $\mathrm{Cu} / \mathrm{S}$ mole ratio with increasing $\mathrm{I}_{2}$ exposure. The error bars indicate 3 replicates of the ICP measurement. 


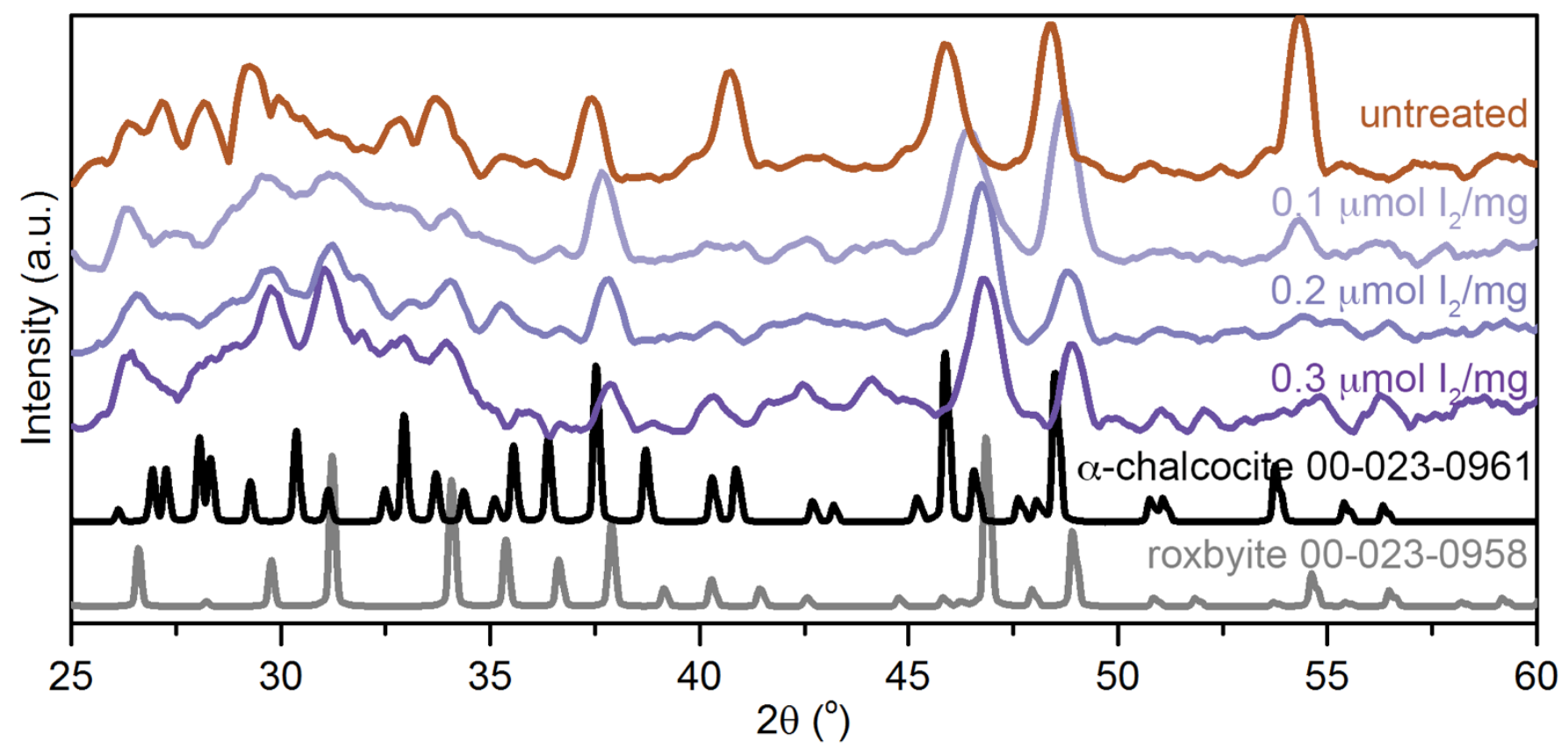

Figure S5. Expanded PXRD of nanorods exposed to different amounts of $\mathrm{I}_{2}$, showing the match to $\alpha$-chalcocite before $\mathrm{I}_{2}$ exposure and the gradual shift towards roxbyite crystal structure.

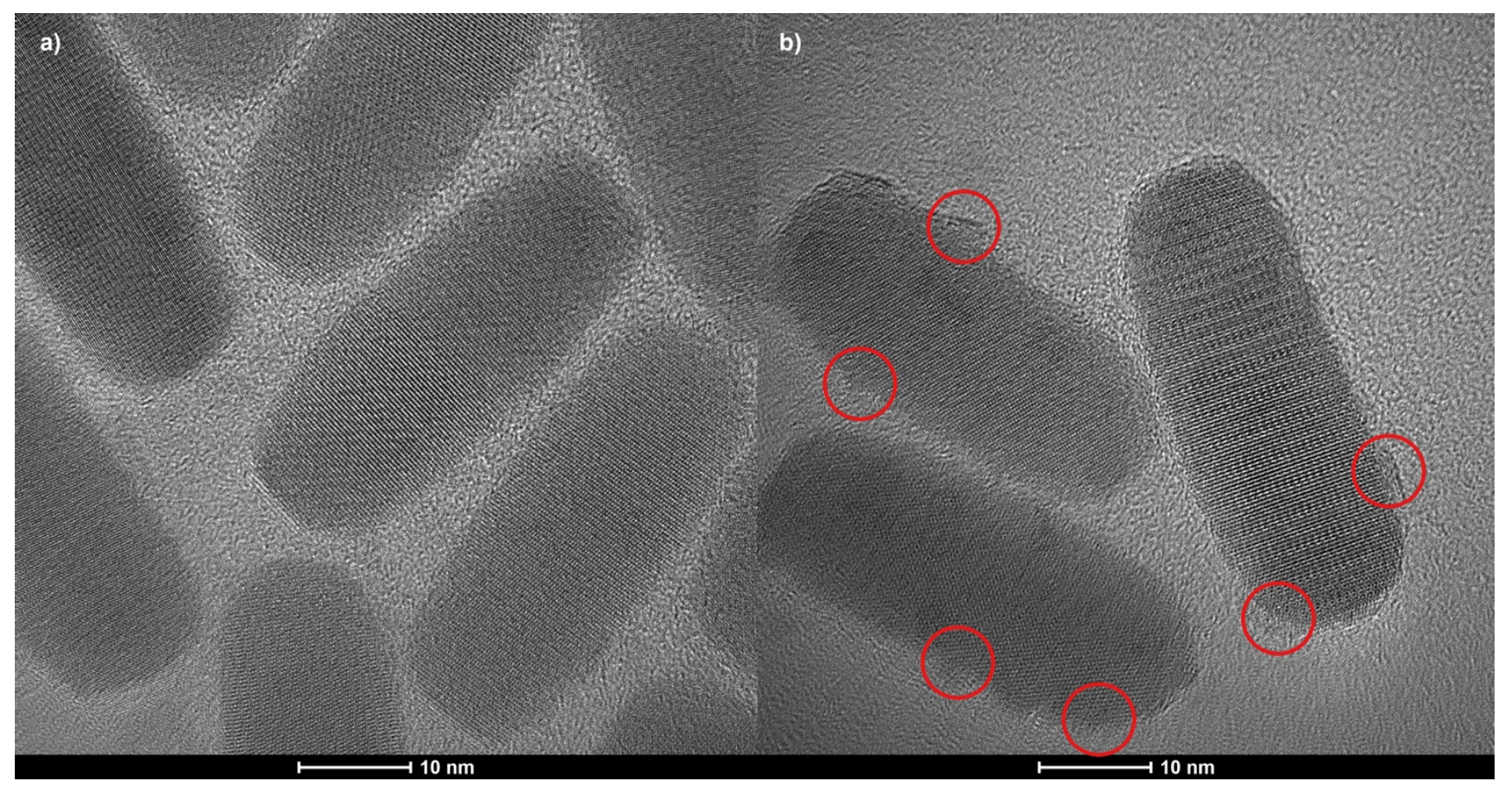

Figure S6. HR-TEM of untreated (left) and $\mathrm{I}_{2}$-exposed (right) roxbyite nanorods, showing that $\mathrm{I}_{2}$ results in roughening of the particle surface with retention of single-crystallinity. 

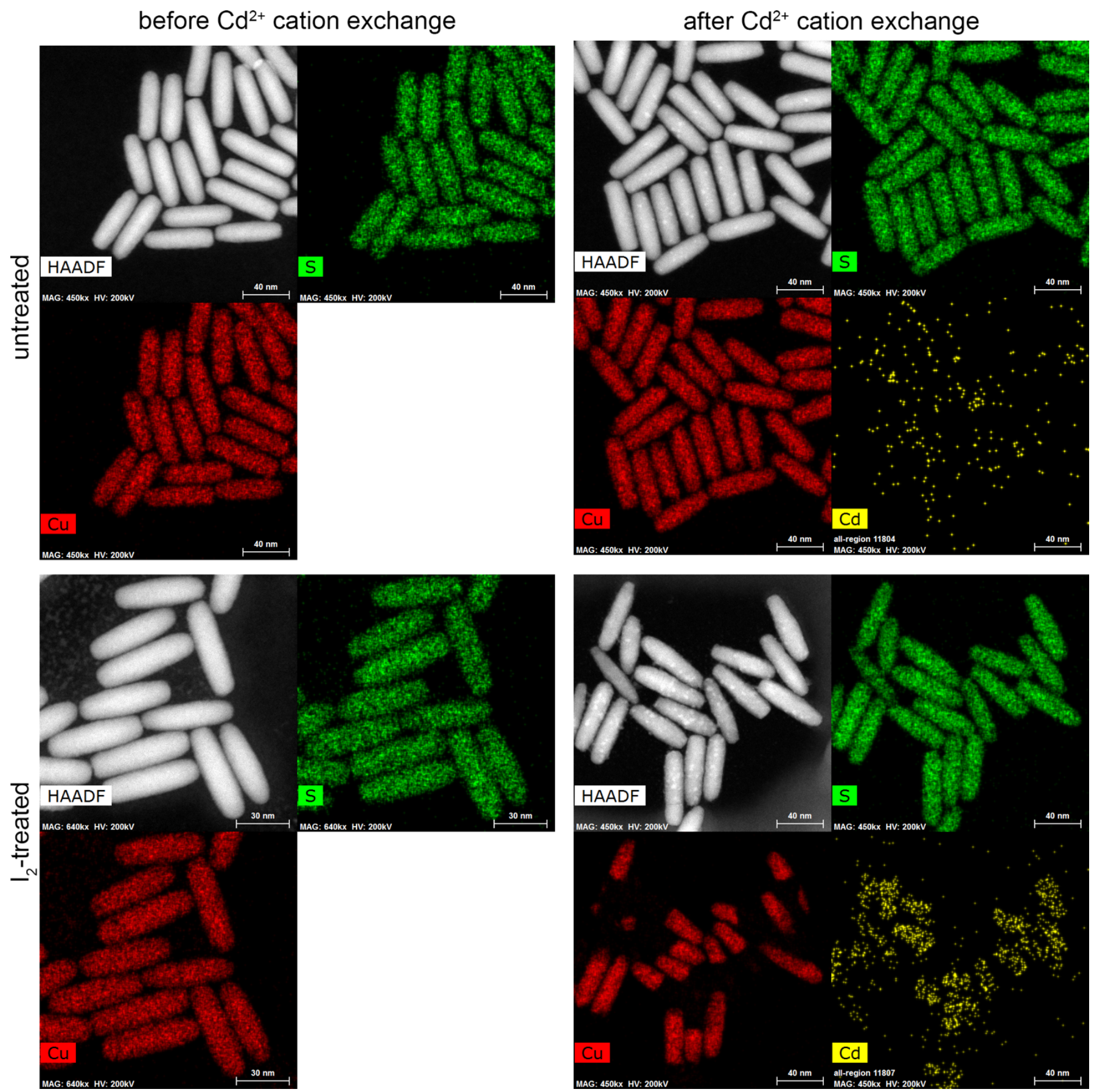

Figure S7. HAADF image and $\mathrm{Cu}, \mathrm{S}$, and $\mathrm{Cd}$ maps for nanorods. A key point is the increase in the amount of Cd in the post-exchanged nanorods in the $\mathrm{I}_{2}$-treated particles. The mottling seen in some of the HAADF images is a beam artifact that occurs over the course of EDS mapping. 

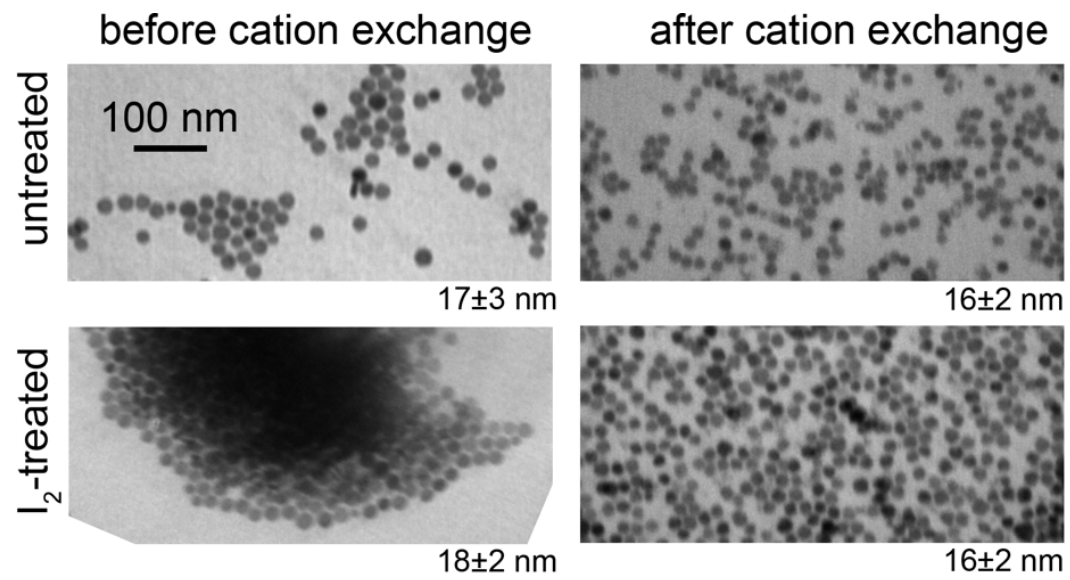

Figure S8. TEM of roxbyite nanoplatelets before and after $\mathrm{I}_{2}$-exposure and/or cation exchange.

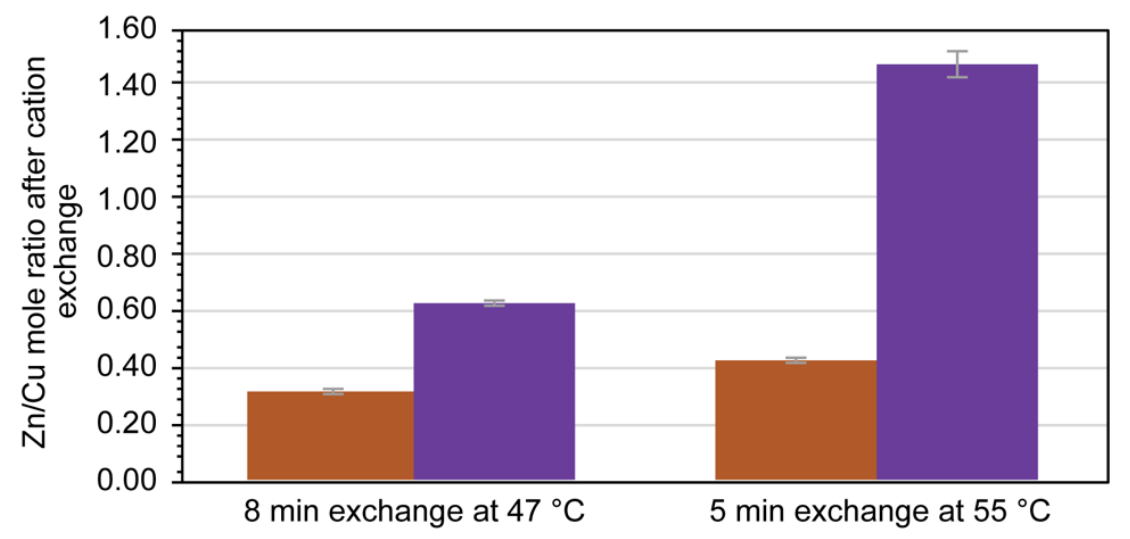

Figure S9. ICP data for platelets before and after exchange showing that $\mathrm{I}_{2}$ exposure increases extent of $\mathrm{Zn}^{2+}$ exchange.

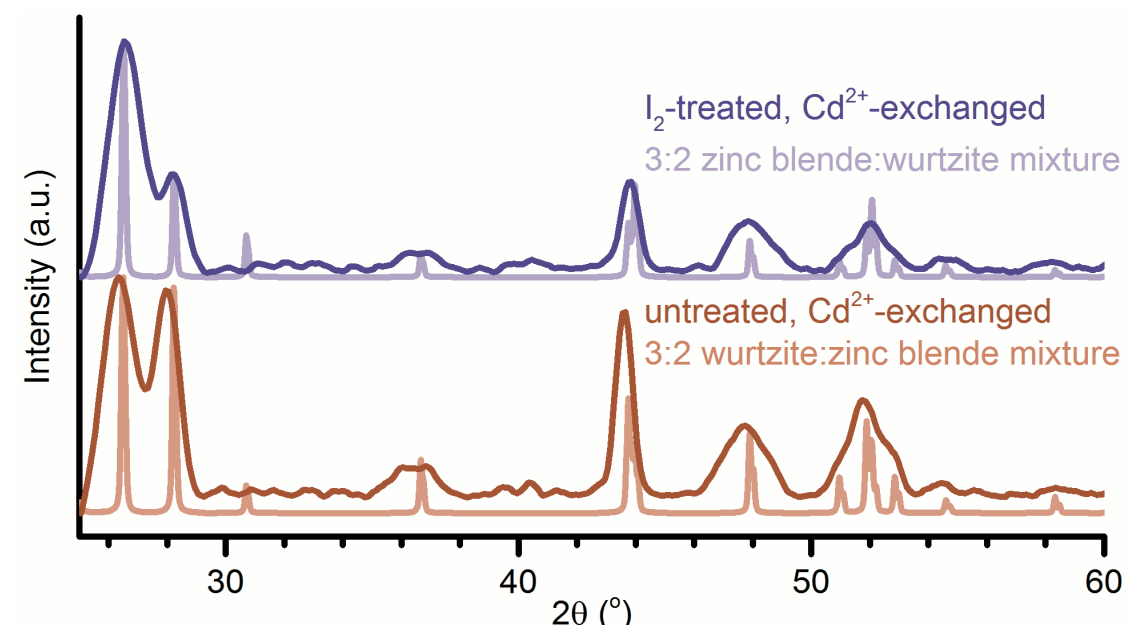

Figure S10. PXRD of roxbyite nanoplatelets after 24 hours of room temperature exchange with $\mathrm{Cd}^{2+}$, showing that a mixture of phases is obtained and that an increased percentage of the cubic zinc blende product is obtained using particles treated with $\mathrm{I}_{2}$. 


\section{REFERENCES}

(1) Kruszynska, M.; Borchert, H.; Bachmatiuk, A.; Rümmeli, M. H.; Büchner, B.; Parisi, J.; Kolny-Olesiak, J. Size and shape control of colloidal copper(I) sulfide nanorods. ACS Nano 2012, 6, 5889-5896.

(2) Fenton, J. L.; Steimle, B. C.; Schaak, R. E. Tunable intraparticle frameworks for creating complex heterostructured nanoparticle libraries. Science 2018, 360, 513517.

(3) Powell, A. E.; Hodges, J. M.; Schaak, R. E. Preserving Both Anion and Cation Sublattice Features during a Nanocrystal Cation-Exchange Reaction: Synthesis of Metastable Wurtzite-Type CoS and MnS. J. Am. Chem. Soc. 2016, 138, 471-474.

(4) Kim, B.-S.; Hong, J.; Hou, B.; Cho, Y.; Sohn, J. I.; Cha, S.; Kim, J. M. Inorganic-ligand exchanging time effect in PbS quantum dot solar cell. Appl. Phys. Lett. 2016, 109,063901

(5) Lan, X.; Voznyy, O.; Kiani, A.; García de Arquer, F. P.; Abbas, A. S.; Kim, G.-H.; Liu, M.; Yang, Z.; Walters, G.; Xu, J.; et al. Passivation using molecular halides increases quantum dot solar cell performance. Adv. Mater. Weinheim 2016, 28, 299-304.

(6) Houck, D. W.; Korgel, B. A. Facile Exchange of Tightly Bonded L-Type Oleylamine and Diphenylphosphine Ligands on Copper Indium Diselenide Nanocrystals Mediated by Molecular Iodine. Chem. Mater. 2018, 30, 8359-8367.

(7) Jain, P. K.; Manthiram, K.; Engel, J. H.; White, S. L.; Faucheaux, J. A.; Alivisatos, A. P. Doped nanocrystals as plasmonic probes of redox chemistry. Angew. Chem. Int. Ed. Engl. 2013, 52, 13671-13675.

(8) Hartstein, K. H.; Brozek, C. K.; Hinterding, S. O. M.; Gamelin, D. R. Copper-Coupled Electron Transfer in Colloidal Plasmonic Copper-Sulfide Nanocrystals Probed by in Situ Spectroelectrochemistry. J. Am. Chem. Soc. 2018, 140, 3434-3442. 